\title{
DE QUAL MEIO AMBIENTE?
}

Ana Luiza Barilli Nogueira, Munir Jorge Felicio

Curso de Comunicação Social da Universidade do Oeste Paulista - UNOESTE - Presidente Prudente-SP.

\section{RESUMO}

A comunicação social se auto reproduz, devido ao desenvolvimento humano, por promover a comunicação e criação cultural. O objetivo do estudo visa ampliar a compreensão da diferença entre realidade fática e midiática refletindo sobre as ações antrópicas. Essa reflexão será impulsionada por intermédio das análises que serão efetuadas em matérias publicadas em um periódico de alcance regional. Após a organização das notícias publicadas e recortadas será construído um banco de dados obedecendo a uma metodologia própria. Ela reunirá os principais conceitos sobre o meio ambiente como, por exemplo, lixo, agrotóxico, sustentabilidade, etc. Esse banco de dados servirá para promover discussões sobre o meio ambiente utilizando as análises de diferentes pesquisadores visando provocar debates e reflexões sobre a importância do meio ambiente e dos impactos destrutivos sobre ele. Essa tarefa é importante para que o futuro comunicólogo amplie sua responsabilidade social, pois é ele o principal profissional construtor da realidade social.

Palavras-chave: meio ambiente, comunicação, realidade, midiática, fática

\section{INTRODUÇÃO}

A comunicação se auto reproduz por causa e em função das relações humanas. Ela gera uma ininterrupta produção cultural, tanto de objetos materiais quanto imateriais. Compreender a reação entre ideologia e comunicação é um ponto chave dentro dessa pesquisa, já que a realidade não se apresenta aos seres humanos a primeira vista. Eles criam suas versões da realidade e assim transmitem aquilo que interpretaram de tal realidade.

Há então a realidade dos fatos, que é imutável e histórica. E há a representação dos fatos, que será alterada de acordo com a intencionalidade de quem criou a representação. A representação dos fatos não mostra uma totalidade, mas sim o que é importante para a pessoa que interpretou aquilo. Então podemos dizer, que existem duas realidades: a realidade fática e a midiática.

A pesquisa gira em torno de uma pergunta: "De qual meio ambiente?". Constataremos ao longo dela a existência de um meio ambiente midiático e a mesma será desenvolvida apresentando reflexões sobre problemas ambientais, que apesar de vários alertas desde a primeira atitude mundial para preservar o meio ambiente, Estocolmo em 1972, não são 
suficientes. O objetivo do estudo foi ampliar a compreensão a respeito da diferença entre realidade fática e midiática voltada ao meio ambiente.

\section{METODOLOGIA}

O desenvolvimento dessa iniciação cientifica foi estabelecida por meio de diálogos com diversos autores visando estabelecer e entender diferentes abordagens e relações entre a comunicação social e o meio ambiente. Com as informações obtidas pela leitura dos pesquisadores será construído um banco de dados pela organização das notícias publicadas e recortadas de um periódico de alcance regional. O banco de dados obedecerá uma metodologia própria na qual está reunida os principais conceitos sobre o meio ambiente como, por exemplo, lixo, resíduos sólidos, fauna, flora, agrotóxico, sustentabilidade, etc. Esse banco de dados servirá para promover discussões sobre o meio ambiente utilizando as análises de diferentes pesquisadores.

\section{RESULTADOS}

Com as concepções retiradas dos textos, concluímos que a comunicação social está em constante desenvolvimento e que ela se desenvolve com o avanço da tecnociência, que esta diretamente ligada a degradação do meio ambiente. Cabe então ao comunicador, utilizar de seu conhecimento e tentar reproduzir ao máximo a realidade fática, mesmo que isso não seja possível, já que ele vai contar a versão daquilo que viu, baseando seu texto em sua visão de mundo e em suas ideologias.

Com esse poder de influenciar as pessoas através das palavras e sendo um formador de opinião é imprescindível o comunicador exercer esse papel e contribuir com a formação da consciência ecológica, que ajudará a sociedade ao longo de sua existência.

\section{DISCUSSÃO}

De acordo com o tempo os assuntos foram surgindo em diferentes conferências e reuniões, como em 1987, na Comissão Mundial sobre o Meio Ambiente e Desenvolvimento, que tratava sobre o desenvolvimento sustentável. E isso foi se tornando cada vez mais continuo. Em 1992 trataram sobre os gases que geram o efeito estufa no Rio-Eco, em 2000 na Holanda falaram sobre os créditos de carbono e uma das ultimas reuniões ocorreu na Conferência Mundial Rio+20 em junho de 2012. 
A crise do conhecimento e a crise da civilização avançaram por causa do "fracionamento do conhecimento e pela degradação do meio ambiente, marcados pelo logocentrismo da ciência moderna e pelo transbordamento da economização do mundo guiado pela racionalidade tecnológica e pelo livre mercado" (LEFF, 2000). Segundo Sen (2008), as pessoas hoje em dia vivem "em média muito mais tempo que no passado, [...], entretanto vivemos igualmente em um mundo de privação, destituição e opressões extraordinárias" (SEM, 2008).

Rossi (1994) defende em sua obra a maneira que os meios de comunicação de massa seduzem as mentes usando uma arma, aparentemente inofensiva: a palavra. Ele diz que o jornalismo não apresenta uma objetividade, mesmo que ela seja buscada. Por isso, a notícia dificilmente não terá os valores, posições e relevâncias de todos aqueles que fizeram a notícia.

A neutralidade começa a ser deixada de lado já na escolha da pauta. Outro ponto de questionamento é a fonte, as assessorias de imprensa, que agem por interesses específicos, conduzem o conteúdo veiculado para saber a maneira que essa informação impactará o público. Rossi (1994) afirma que o dever de um jornalista é para com a sociedade, então as notícias devem ser verificadas, aprofundadas e transmitidas com clareza para que o público possa tirar suas próprias conclusões sobre o assunto. Mas não é isso que ocorre, já que a população foi condicionada a não analisar o conteúdo que recebe. Os meios de comunicação fizeram com que as pessoas se tornassem meras espectadoras de um conteúdo que visa atender uma minoria.

Para Bordenave (2006), a necessidade de uma população define o nível de comunicação que ela terá, ou seja, a comunicação é o meio social onde ela está incluída e ela está presente em todos os lugares, já que o ser humano está em constante troca de informações.

Ele também diz que as formas de manipulação e linguagem indicam duas realidades: a objetiva e a redesenhada pelo discurso de comunicação. A segunda está ligada aos interesses de proprietários dos meios veiculadores de informação, que usam de seu grande público para manipular as informações. Isso faz com que a possibilidade de construir uma sociedade participativa acabe sendo menosprezada.

Mcluhan (2007) compreende o desenvolvimento dos meios de comunicação como sendo uma extensão de corpo do ser humano. A partir disso, ele constrói coisas que o ajudam a concluir seus objetivos. Também analisa a rede de comunicação em que o ser humano está imerso e que diretamente, afeta sua visão e experiência do mundo, de si mesmo e dos outros. Por meio dessas análises concluímos que as tecnologias ampliaram as extensões do corpo e da inteligência humana. 
Já Martin-Barbero e Rey (2001) refletem sobre as complexidades de linguagens e escrituras das imagens. Eles estudaram a preferência do ser humano pela imagem, a transformação do desejo do saber no desejo de ver. Esse incremento é o que impulsiona as redes sociais, os blogs e direcionam a mídia a novos caminhos, para um novo olhar. E com esse novo olhar emerge a crise de representação na mídia, os espaços deixam de ser domésticos e coletivos e passam a ser difusos e homogênios.

Eles discutem o poder dos meios de comunicação de massa, como sendo um modificador do imaginário das pessoas, que acabam confundindo a essência, enxergando apenas a aparência.

Para distingui-las Kosik (1985) explica que o ser humano não vê a realidade à primeira vista. Ele "cria suas próprias representações das coisas e elabora todo um sistema correlativo de noções que capta e fixa o aspecto fenomênico da realidade" (KOSIK, 1995). Esse aspecto fenomênico da realidade é captado pelo ser humano, mas não é suficiente para compreender o fenômeno. Para o fenômeno ser compreendido é preciso atingir a essência e não somente a aparência.

Por meio dos recursos tecnológicos de aperfeiçoamento do real aumenta a fascinação pelo ideal e a medida que os meios de comunicação de massa controlam e dominam esses limites aumenta-se a influencia na sociedade, como mostra a pesquisa de Felício et al. (2011).

\section{CONCLUSÃO}

Os meios de comunicação de massa influenciam a sociedade, através de mecanismos manipuladores, para atender os objetivos de empresas particulares e o conteúdo absorvido pela população passa a ser um conteúdo que não é real, um conteúdo midiático.

Então a partir de todos esses autores podemos concluir que a comunicação social é dinâmica e o seu desenvolvimento é impulsionado pelo avanço da tecnologia e seu avanço gera impactos que atingem diretamente o meio ambiente.

É necessário para um comunicólogo saber que formará opiniões e que irá construir uma realidade social, então esse profissional deve levar em consideração que atuará em um mercado globalizado e homogêneo e deve tentar ao máximo expor a realidade como ela é. E como formador de opinião deve contribuir com o crescimento da consciência ecológica. 


\section{REFERÊNCIAS}

ARBEX JUNIOR, J. Showrnalismo: a notícia como espetáculo. 4 ed.São Paulo: Casa Amarela, 2002.

BORDENAVE, J.D. O que é comunicação, São Paulo: Brasiliense, 2006.

FELICIO, M.J.; SAMIZAVA, F.M.; NICOLETTI, T.B. et al. As condições históricas para a produção de sentido, Presidente Prudente: Revista Identidade Cientifica, 3ed., v. 3, p. 1-11, 2011.

KOSIK, K. Dialética do Concreto. 1ed., Rio de Janeiro: Paz e Terra, 1985.

KUNZLER, C. M. A Teoria dos Sistemas de Niklas Luhmann. Estudos de sociologia, Araraquara, n. 16, p. 123-136, 2004.

LEFF, E. Complexidade, Interdisciplinaridade e Saber Ambiental. In: PHILIPPI JUNIOR, A.; TUCCI, C. E. M.; HOGAN, D. J.; NAVEGANTES, R. Interdisciplinaridade em Ciências Ambientais, São Paulo: Signus, p. 19-51, 2000.

MCLUHAN, M. Os meios de comunicação como extensões do homem. 1ed., São Paulo: Cultrix, 2007.

MARTIN-BARBERO, J.; REY, G. Os exercícios de ver: Hegemonia audiovisual e ficção televisiva, 1 ed., São Paulo: Editora Senac, 2001.

MAZOYER, M.; ROUDART, L. História das agriculturas do mundo: de neolítico à crise contemporânea. 1ed., Lisboa: Histórias e Monografias, 1998.

SEN, A. Desenvolvimento como liberdade. 1ed., São Paulo: Companhia das Letras, 2008.

SÓGLIO, F. K. D. O desenvolvimento rural no Brasil e na America Latina: como estão nossos projetos. In: ALMEIDA, J.; MACHADO,J.A.D. Desenvolvimento rural no Cone Sul. Desrrollo Rural em el Cono Sur. Porto Alegre: Associação Holos Meio Ambiente e Desenvolvimento, p. 311-336, 2009.

ROSSI, C. O que é jornalismo. 1ed., São Paulo: Brasiliense, 1994. 